\section{Review process}

The journal operates a policy of anonymous, expert, peer review. Papers will be subject to an initial review by the Editor and usually a minimum of two independent reviewers. Authors are able to follow the progress of their submission through the online system. Authors will be notified of the outcome of their submission within the shortest time possible and the journal aims for a one to three months turnaround. Of course, the journal is reliant upon its volunteer reviewers and these times may vary.

\section{Instructions to authors}

- Submissions are expected to be theoretically grounded and methodologically sound.

- Authors are expected to prepare their manuscript (including references) in line with the APA 6th Edition style guide

- One main article should be submitted with a separate file with full contact details.

- Manuscripts must be typed in double spacing with margins of a minimum of two centimetres.

- All manuscripts should begin with an Abstract, of not more than 250 words, describing the salient information about Background, Aims, Sample, Methods, Results and Conclusions.

- Tables and figures, accompanied by their title, should be typed in double spacing, one per page.

- Tables and figures should be placed at the end of the manuscript and an indication of where they are to be inserted (e.g., 'Insert Table 1 here') should be present in the manuscript's text, close to where the table/figure is referred to.

- Wherever possible and if applicable effect size should be indicated.

- Authors are expected to write in an inclusive manner in reference to gender, and ability/disability.

- Authors are responsible for acquiring written permission to publish lengthy quotations, illustrations etc for which they do not own copyright.

- Authors are responsible for ensuring that the research described has been gathered, analysed and presented in the most ethically and scientifically respectful and rigorous manner. Authors must include all required statements (outlined below), which should be placed at the end of the text (before the References section).

- Authors must ensure that there are no means of establishing authorship from the text.

\section{Manuscript length}

Papers should normally be no more than 6,000 words (Including all references and other content) although the Editor retains discretion to publish papers beyond this length in cases where the clear and concise expression of the scientific content requires greater length.

Brief reports (less than 3,500 words) are also welcome. Please indicate at submission which type of paper is being submitted.

Book Reviews (up to 500 words) are also welcomed. Please contact the Book Reviews Editor before submission.

\section{Criteria for publication}

In making your report you are requested to pay attention to the following points:

\section{The paper}

- is sufficiently theoretically and empirically grounded

- is sufficiently original

- clearly advances knowledge and practice in educational and developmental psychology
- contains balanced syntheses, summaries, arguments, and conclusions

- has clear grammar, syntax, and expression

- is ordered

- is free of faults in experimental procedure, proposed application, or theoretical reasoning

- is free of errors in mathematics, calculations, units, etc

- is parsimonious and reads well

- has correctly labelled figures and tables

- has correctly written and appropriate references, free from obvious omissions.

\section{Communication with the Editor}

All manuscripts will be acknowledged and reviewed by the Editorial Board or by invited reviewers.

Dr Chris Boyle

Faculty of Education,

Monash University

Melbourne

Australia

Christopher.boyle@monash.edu

\section{Digital submission guidelines}

Manuscripts should be submitted online via our manuscript submission and tracking site, http://mc.manuscriptcentral. com/aedp. Full instructions for electronic submission are available directly from this site. To facilitate rapid reviewing, communications for peer review will be electronic and authors will need to supply a current e-mail address when registering to use the system.

Submission of a manuscript will be taken to imply that all listed authors have seen the final version and approved it.

\section{Copyright}

It is the policy of the Australian Psychological Society to own the copyright to its publications, and to the contributions contained therein, in order to protect the interests of the Society and its authors, and at the same time to facilitate the appropriate reuse of this material by others. Therefore, upon acceptance of their manuscript for publication, authors will be asked to fill in a copyright transfer form (http://journals.cambridge.org/images/ fileUpload/documents/EDP_ctf.pdf) and return to the production Editor at Cambridge University Press. Publication of the manuscript will be contingent upon receipt of this form. Publications of the Society are distributed to various other publications for review and abstracting purposes. In addition, the Society has contractual agreements with various secondary publishers for the republication, in hard copy, microfilm, or digital form, of individual articles and journal issues as a whole. It is the Society's position that the abstracts that are published with its journal articles are indicative of and not a substitute for, the work as a whole; therefore, access services are allowed free use of these abstracts without securing the permission of the Society. Enquiries about policy and procedures relating to permission to reproduce material published in the journal should be directed to the Australian Psychological Society.

\section{Disclosure}

'The publication of an advertisement by the Australian Psychological Society is not an endorsement of the advertiser nor of the products and services advertised. Only those professional development activities carrying the APS logo and an appropriate endorsement statement can be considered to be specifically approved by the APS. Advertisers may not incorporate in a subsequent advertisement or promotional piece the fact that a product or service has been advertised in any publication of the Society. 


\section{Contents}

Volume 3 I No. I

July 2014
Editorial

Psychology in the Topics

Christopher Boyle

Articles

From Stability to Mobility: African Secondary School Aged

Adolescents' Transition to Mainstream Schooling

1

Sashya Gunasekera, Stephen Houghton, Kenneth Glasgow and

Christopher Boyle

Social Media Use and Social Connectedness in Adolescents:

The Positives and the Potential Pitfalls

Kelly A. Allen, Tracii Ryan, DeLeon L. Gray, Dennis M. Mclnerney and Lea Waters

Predicting Motor Skills From Strengths and Difficulties

Questionnaire Scores, Language Ability, and Other Features of New Zealand Children Entering Primary School

Rebecca J. Sargisson, Cheniel Powell, Peter Stanley and

Rosalind de Candole

Psychotherapy, Pharmacotherapy, and Their Combination for Adolescents with Major Depressive Disorder: A Meta-Analysis Nikita Singh and John Reece

Second Language Developmental Dynamics: How Dynamic Systems Theory Accounts for Issues in Second Lanquage Learning Rosmawati

Book Reviews

Assessment for Teaching

Jacqueline Harvey

Improving Learning Through Dynamic Assessment: A Practical Classroom Resource

Aimee Maxwel

Ethical Practice in Applied Psychology

iii

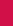

(n)

